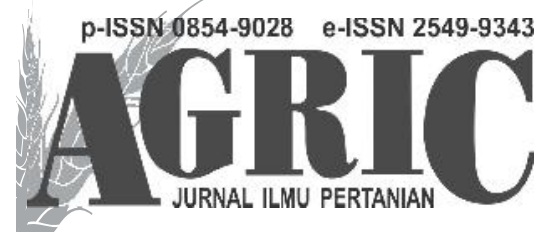

Fakultas Pertanian dan Bisnis Universitas Kristen Satya Wacana

JI. Diponegoro 52-60 SALATIGA 50711 - Telp. 0298-321212 ext 354

email: jurnal.agric@adm.uksw.edu, website: ejournal.uksw.edu/agric

PREFERENSI PETANI TERHADAP BEBERAPA VARIETAS BAWANG MERAH KASUS DESA PASIR, KECAMATAN MIJEN, KABUPATEN DEMAK

\title{
FARMER PREFERENCES FOR SHALLOT VARIETIES: EVIDENCE FROM PASIR VILLAGE, MIJEN DISTRIC DEMAK REGENCY
}

\author{
Shofia Nur Awami, Sri Wahyuningsih, Rina \\ Program Studi Agribisnis Fakultas Pertanian \\ Universitas Wahid Hasyim Semarang
}

E-mail: shofifaperta@unwahas.ac.id,wahyuningsih281169@gmail.com,rinasuyitno5@gmail.com

Diterima: 29 Maret 2019, disetujui 13 Desember 2019

\begin{abstract}
Mijen district is the highest shallot producing area in Demak Regency. The purpose of this research are to know; 1) the attributes characteristics that influenced farmers in choosing shallots planted, 2) The shallot variety that has highest planting frequency, and 3) Comparison of attribute of some shallot varieties that are often planted by farmers in Pasir Village. This research used descriptive method while location sampling has done purposively. The research location are Pasir Village, Mijen District. Sampling of farmers was carried out by purposive sampling, with respondents involved as many as 42 farmers, taken from 2 selected farmer groups, namely Tani Jaya farmer groups as many as 21 and Tani Makmur 21 people. Data analysis uses tabulation and perceived quality methods. The results showed that the shallot characteristics were considered by the farmers namely the age of harvest (0.18) and production yield (0.17). Farmers prefer to cultivated shallot of Bima Brebes varieties (the first planting season). Farmers planted Bima Sawo variety in the second planting season. The total preference level value obtained showed that the TPT of the Bima Curut variety is the most preferred compared to other varieties, with a value of 1.02 .
\end{abstract}

Keywords: Varieties, shallot, Bima Brebes, Pasir Village. 


\begin{abstract}
ABSTRAK
Kecamatan Mijen merupakan daerah penghasil bawang merah tertinggi di Kabupaten Demak. Penelitian ini bertujuan untuk mengetahui: 1). Karakteristik atribut yang menjadi pilihan petani saat menanam bawang merah, 2). Varietas bawang merah yang mempunyai frekuensi penanaman tertinggi, dan 3). Perbandingan karakteristik atribut beberapa varietas bawang merah yang sering ditanam petani di Desa Pasir. Penelitian ini menggunakan metode deskriptif dan pemilihan lokasi dengan cara purposive sampling. Lokasi penelitian adalah Desa Pasir Kecamatan Mijen. Pengambilan sampel petani dilakukan secara purposive sampling, dengan responden yang dilibatkan sebanyak 42 petani, yang diambil dari 2 kelompok tani yang terpilih yaitu kelompok tani Tani Jaya sebanyak 21 dan Tani Makmur 21 orang. Analisis data menggunakan metode analisis tabulasi dan perceived quality. Hasil penelitian menunjukkan bahwa karakteristik atribut pada tanaman bawang merah yang dianggap penting oleh petani yaitu umur panen $(0,18)$ dan hasil produksi $(0,17)$. Petani bawang merah lebih banyak menanam Varietas Bima Brebes (Musim tanam I), sementara musim tanam II petani bawang merah lebih banyak menanam bawang merah varietas Bima Sawo. Nilai tingkat preferensi total yang diperoleh menunjukkan bahwa TPT nilai varietas Bima Curut yang paling disukai dibandingkan varietas lain, dengan nilai 1,02.
\end{abstract}

Kata Kunci: Varietas, bawang merah, Bima Brebes, Desa Pasir.

\section{PENDAHULUAN}

Bawang merah merupakan salah satu komoditas sayuran unggulan di Indonesia. Selain berfungsi sebagai bumbu masakan, bawang merah dapat digunakan sebagai obat tradisional. Salah satu sentra produksi bawang merah di Indonesia adalah Provinsi Jawa Tengah. Menurut Pusat Data dan Sistem Informasi Pertanian tahun 2015, pada periode tahun 2010-2014 (lima tahun terakhir), ratarata pertumbuhan luas panen bawang merah di Indonesia naik sebesar $3,70 \%$ per tahun. Sementara rata-rata pertumbuhan luas panen bawang merah di Jawa, pada periode tahun 1980-2014 sebesar 4,29\% per tahun. Keempat provinsi sentra bawang merah (Jawa Tengah, Jawa Timur, Jawa Barat, serta Nusa Tenggara Barat), memberikan kontribusi sebesar $86,24 \%$ terhadap rata-rata produksi bawang merah Indonesia. Provinsi Jawa Tengah memberikan kontribusi terbesar yaitu $42,70 \%$ dengan rata-rata produksi sebesar 439.851 ton. Sementara pada tahun 2016,
Jawa Tengah dapat memproduksi bawang merah sebesar 5.466.846 Kuintal dengan luas panen sebesar 53.331 ha. Selain Kabupaten Brebes, Kabupaten Demak, Pati dan Kendal juga merupakan daerah penghasil bawang merah tertinggi di Jawa Tengah.

Pada Tahun 2016, Kabupaten Demak memiliki luas panen $6.218 \mathrm{Ha}$, produksi sebesar 599.053 kuintal, serta produktivitas sebesar 96,34 ku/Ha. Kecamatan Mijen merupakan kecamatan yang masuk dalam wilayah Kabupaten Demak, serta merupakan kecamatan tertinggi penghasil bawang merah dalam periode 3 tahun terakhir. Adapun data produksi bawang merah di Kabupaten Demak, dalam periode tiga tahun terakhir berturut-turut tahun 2014-2016 dapat dilihat pada Tabel 1. Produksi bawang merah di Kecamatan Mijen mengalami peningkatan dalam kurun waktu 3 tahun tersebut.

Guna memperoleh produk bawang merah yang berkualitas, maka benih yang digunakan petani haruslah benih yang bermutu. Terdapat 
beberapa varietas bawang merah yang sering digunakan petani dalam budidaya bawang merah. Sementara, Indonesia telah mempunyai 32 varietas bawang merah, yang telah dilepas oleh Menteri Pertanian. Varietas bawang merah yang ditanam di sentra produksi Jawa Tengah dan Jawa Barat diantaranya adalah Kuning, Bima Brebes, Bima Timor, Bima Sawo, Bangkok, dan Philippines.

Menurut Basuki (2014), hasil penelitiannya menunjukkan bahwa persepsi petani Brebes terhadap varietas bawang merah, varietas Bima Brebes mempunyai kualitas paling baik dibanding varietas lainnya. Secara kualitatif, kualitas varietas Bima Brebes 15\% di atas kualitas varietas Mentes, $31 \%$ di atas Katumi, 23\% di atas Pancasona, 35\% diatas Pikatan, $10 \%$ diatas Sembrani, dan Trisula. Mayoritas petani $(67 \%)$ menyukai varietas Bima Brebes. Varietas Bima Brebes merupakan salah satu varietas bawang merah yang dilepas oleh Balitsa pada tahun 1984. Cocok ditanam di dataran rendah, produksi umbi kering dapat mencapai
9,9 ton/ha serta cukup tahan terhadap penyakit busuk umbi (Direktorat Jendral Hortikultura Kementerian Pertanian, 2018).

Sementara di Kabupaten Demak, kebanyakan petani juga menggunakan varietas Bima Brebes, juga varietas lainnya yang dikenal masyarakat setempat dengan sebutan varietas Bima Curut, Bima Drajat, serta varietas lain seperti Sarkonah. Berdasarkan uraian tersebut, maka penelitian ini bertujuan untuk mengetahui: 1). atribut yang menjadi pilihan petani saat menanam varietas bawang merah, 2). varietas bawang merah yang lebih banyak ditanam oleh petani, 3). perbandingan atribut beberapa varietas bawang merah yang sering ditanam petani.

\section{METODE PENELITIAN}

Penelitian ini dilaksanakan di Desa Pasir Kecamatan Mijen Kabupaten Demak dengan metode survey. Pengambilan daerah penelitian ditentukan dengan metode purposive. Pemilihan lokasi penelitian ditentukan secara sengaja berdasarkan pertimbangan tertentu,

Tabel 1 Produksi Bawang Merah Tiap Kecamatan di Kabupaten Demak

\begin{tabular}{lrrr}
\hline \multirow{2}{*}{ Kecamatan } & \multicolumn{2}{c}{2014} & \multicolumn{1}{c}{2016} \\
\cline { 2 - 4 } & $\begin{array}{r}\text { Produksi } \\
(\mathrm{Ha} / \mathrm{Kw})\end{array}$ & $\begin{array}{r}\text { Produksi } \\
(\mathrm{Ha} / \mathrm{Kw})\end{array}$ & $\begin{array}{r}\text { Produksi } \\
(\mathrm{Ha} / \mathrm{Kw})\end{array}$ \\
\hline Demak & 22.030 & 30.785 & 40.380 \\
Bonang & 140 & 337 & 965 \\
Wonosalam & 6.232 & 1.670 & 7.383 \\
Dempet & 51.777 & 61.840 & 81.629 \\
Kebonagung & 2.990 & 371 & 744 \\
Karangtengah & - & - & - \\
Guntur & 3.645 & 351 & 640 \\
Sayung & - & - & - \\
Mranggen & - & - & - \\
Karangawen & 109 & - & - \\
Mijen & 160.925 & 281.511 & 317.755 \\
Wedung & 25.370 & 26.971 & 4.675 \\
Gajah & 11.383 & 7.927 & 90.465 \\
Karanganyar & 87.210 & 77.220 & \\
\hline
\end{tabular}

Sumber: Dinas Pertanian Kabupaten Demak, 2016 
yaitu Desa Pasir Kecamatan Mijen Kabupaten Demak merupakan daerah penghasil bawang merah dan pemasok terbesar di Demak dan sekitarnya. Produksi bawang merah di Desa Pasir dapat mencapai 5.905,4 Ton dengan luas lahan 321,46 Ha (Monografi Desa Pasir, 2017).

Pada penelitian ini 42 responden diambil dari 2 kelompok tani yang terpilih yaitu kelompok tani Tani Jaya sebanyak 21 dan kelompok tani Makmur 21 orang. Kedua kelompok tani tersebut merupakan kelompok tani yang aktif serta kelompok tani yang disahkan oleh Menteri Hukum dan HAM Republik Indonesia sejak 2015. Kelompok tani dikategorikan aktif dalam penelitian ini berdasarkan indikator keaktifannya setiap minggu mengadakan kegiatan rutinitas kelompok dan mengikuti kegiatan seminar pertanian bawang merah di berbagai daerah.

Jenis data yang digunakan dalam penelitian ini adalah data primer dan sekunder. Guna menjawab tujuan pertama, karakteristik atribut yang mempengaruhi petani dalam memilih varietas bawang merah, menggunakan data dan informasi melalui kuisioner. Prosedur perhitung-an untuk mengetahui tingkat preferensi petani terhadap atribut karakteristik tanaman bawang merah menggunakan teknik perhitungan perceived quality (PQ) (Simamora, 2002). Teknik ini diawali dengan penentuan atribut karakteristik tanaman bawang merah yang diperkirakan menjadi pertimbangan petani dalam memilih varietas bawang merah yang disukai. Dalam hal ini, karakteristik tanaman yang ditentukan adalah tinggi tanaman, jumlah anakan/umbi, ketahanan terhadap HPT (Hama penyakit tumbuhan), umur panen, hasil produksi serta bibit mudah didapat/diperoleh.
Perhitungan karakteristik atribut yang dipentingkan oleh petani bawang merah di Desa Pasir dalam menggunakan varietas bawang merah.

1. Tingkat Kepentingan (bobot) atribut karakteristik (BA), misalnya untuk atribut jumlah anakan/umbi, ditentukan ditentukan melalui skoring menggunakan pertanyaan. Skor yang diberikan jika petani menjawab sangat penting $=5$, penting $=4$, biasa saja $=3$, tidak penting $=2$, sangat tidak penting $=1$.

2. Bobot atribut karakteristik rata per responden (BAR) diperoleh dari jumlah skor BA semua petani responden dibagi jumlah responden.

3. Bobot relatif atribut (BRA) merupakan skor BAR peratribut dibagi skor total semua atribut. Sementara untuk mengetahui varietas bawang merah yang mempunyai frekuensi penanaman tertinggi, menggunakan tabulasi data berdasarkan jawaban petani responden melalui kuisioner. Guna menjawab perbandingan karakteristik atribut beberapa varietas bawang merah yang sering ditanam petani menggunakan teknik perhitungan perceived quality(PQ) seperti yang disampaikan Simamora (2002) dan Fachrista (2012). Adapun perhitungan prefe-rensi petani terhadap atribut masing-masing varietas bawang merah, sebagai berikut:

1. Tingkat preferensi petani responden terhadap atribut karakteristik varietas (TP). Nilai TP diukur melalui skoring dengan memberikan pertanyaan. Skor yang diberikan jika petani menjawab sangat suka $=5$, suka $=4$, biasa saja $=3$, tidak suka $=2$, dan sangat tidak suka $=1$.

2. Tingkat preferensi rerata per responden (TPR) diperoleh dari jumlah skor TP semua responden dibagi dengan jumlah responden. 
3. Tingkat preferensi rerata per atribut karakteristik dari semua varietas (TPRA) merupakan jumlah skor TPR per atribut karakteristik semua varietas dibagi dengan jumlah varietas.

4. Tingkat preferensi relatif (TPRel) diperoleh dengan cara membagi skor TPR dengan skor TPRA.

5. Tingkat preferensi relatif dibobot (TPRD) diperoleh dengan cara mengalikan skor RA dengan TPRel.

6. Tingkat preferensi total (TPT) petani terhadap setiap varietas merupakan jumlah skor TPRD dari semua atribut karakteristik yang dimiliki oleh varietas.

\section{HASIL DAN PEMBAHASAN}

Salah satu upaya untuk mendukung pembahasan dalam penelitian ini adalah mengetahui latar belakang petani yang diteliti berkaitan dengan pengaruhnya terhadap kegiatan yang dilakukan responden. Secara umum gambaran responden dapat dilihat dari aspek umur responden, tingkat pendidikan, lama menekuni usaha, jabatan dalam kelompok tani, pekerjaan utama, luas lahan, serta jumlah anggota keluarga. Adapun gambaran karakteristik petani responden yang dilibatkan dalam penelitian, terperinci dalam Tabel 2.

Usia sebagian besar petani responden masuk dalam kategori usia produkstif. Rata-rata tingkat pendidikan petani hanya setingkat Sekolah Dasar (SD) dan beberapa tamatan Sekolah Lanjutan Tingkat Pertama (SLTP). Lama petani menekuni usahatani bawang merah, berada pada kisaran 10-20 tahun. Sementara jabatan dalam kelompok tani adalah jabatan/posisi dalam kelompok tani yang dimiliki oleh petani responden yang terlibat dalam penelitian, dimana kebanyakan petani sebagai anggota dalam kelompok tani.

Luas lahan merupakan seberapa luas lahan yang digunakan petani untuk menanam bawang merah, yang berdasarkan kepemilikannya ada yang lahan milik sendiri dan ada yang lahannya merupakan lahan sewa. Petani yang memiliki lahan sendiri dapat mengusahakan lahannya secara bebas dan tanpa ada beban tanggungan membayar sewa lahan. Pembiayaan yang muncul biasanya berupa biaya pajak lahan. Gambaran status kepemilikan lahan dapat dilihat pada Tabel 3 . Sebesar 60,05 persen, lahan yang digunakan untuk budidaya bawang merah merupakan lahan milik sendiri, sementara sisanya merupakan lahan sewa.

\section{Atribut yang Menjadi Pertimbangan Petani Memilih Varietas Bawang Merah}

Desa Pasir sebagai salah satu desa sentra penghasil bawang merah di Kecamatan Mijen, secara umumnya terdapat 3 kali musim tanam per tahunnya. Periode musim tanam yaitu musim tanam I (Oktober-Desember) ditanam bawang merah, musim tanam II (pada bulan FebruariApril), biasanya dengan sistem tumpang sari yaitu bawang merah dengan tanaman padi atau kacang panjang. Sementara musim tanam III (bulan Juli-Agustus) ditanami bawang merah. Karakteristik kualitas dan hasil bawang merah sangat penting untuk diketahui karena karakteristik menentukan kesediaan petani menanam benih suatu varietas tertentu. Jika atribut kualitas tidak disukai petani maka petani tidak akan bersedia menanam varietas baru tersebut. 
Preferensi petani terhadap karakteristik bawang merah ditampilkan pada Tabel 4 .

Hasil analisis data bobot atribut rerata (BAR) terhadap karakteristik bawang merah menunjukkan bahwa umur panen dipilih sebagai karakter yang paling penting. Berdasarkan nilai BAR secara berturut-turut tingkat kepentingan atribut adalah umur panen $(0,18)$, selanjutnya atribut hasil produksi $(0,17)$. Sementara jumlah anakan, tinggi tanaman, bibit yang mudah diperoleh, dan ketahanan terhadap serangan hama dan penyakit (masing-masing memperoleh 0,16). Umur panen merupakan atribut paling penting menurut petani $(0,18)$, dengan pertimbangan petani lebih memilih tanaman yang berumur pendek karena lebih cepat melakukan pemanenan. Hasil penerimaan ataupun pendapatan panen bawang merah dapat dijadikan modal untuk memulai usahatani bawang merah di musim tanam berikutnya. Hal ini selaras dengan penelitian Setyorini (2018) yang menyatakan rata-rata pendapatan petani Desa Pasir dari berusahatani bawang merah

Tabel 2 Identitas Responden Berdasarkan Umur, Tingkat Pendidikan, Lama Menekuni Usahatani Bawang Merah, Jabatan dalam Kelompok Tani, Luas Lahan Petani

\begin{tabular}{|c|c|c|c|c|}
\hline Umur Responden & Tani Jaya & Persentase (\%) & Tani Makmur & Persentase (\%) \\
\hline$<30$ & 0 & 0 & 0 & 0 \\
\hline $31-40$ & 7 & 33,3 & 5 & 23,8 \\
\hline $41-50$ & 8 & 38,1 & 8 & 38,1 \\
\hline $51-60$ & 5 & 23,8 & 8 & 38,1 \\
\hline$>60$ & 1 & 4,8 & 0 & 0 \\
\hline Jumlah & 21 & 100 & 21 & 100 \\
\hline Rerata umur & 45,5 tahun & \multicolumn{3}{|c|}{46,9 tahun } \\
\hline Pendidikan Terakhir & Tani Jaya & $\begin{array}{c}\text { Persentase } \\
(\%)\end{array}$ & Tani Makmur & Persentase $(\%)$ \\
\hline Tidak bersekolah & 0 & 0 & 0 & 0 \\
\hline SD & 15 & 71,4 & 12 & 57,2 \\
\hline SMP/MTS & 4 & 19,1 & 9 & 42,8 \\
\hline \multirow[t]{2}{*}{ SMA/MA } & 2 & 9,5 & 0 & 0 \\
\hline & 21 & 100 & 21 & 100 \\
\hline Rerata pendidikan & 5,25 tahun/SD & & 5 tahun/SD & \\
\hline Lama Menekuni Usaha & Tani Jaya & Persentase (\%) & Tani Makmur & Persentase (\%) \\
\hline $1-10$ & 3 & 14,3 & 4 & 19,1 \\
\hline $11-20$ & 10 & 47,6 & 12 & 57,1 \\
\hline $21-30$ & 6 & 28,6 & 4 & 19,1 \\
\hline $31-40$ & 2 & 9,5 & 1 & 4,7 \\
\hline Jumlah & 21 & 100 & 21 & 100 \\
\hline $\begin{array}{l}\text { Rerata lama menekuni } \\
\text { usahatani }\end{array}$ & 18,83 tahun & & 16,45 tahun & \\
\hline Jabatan & Tani Jaya & Persentase $(\%)$ & Tani Makmur & Persentase $(\%)$ \\
\hline Ketua & 1 & 4,8 & 1 & 4,8 \\
\hline Bendahara & 1 & 4,8 & 1 & 4,8 \\
\hline Sekretaris & 1 & 4,8 & 1 & 4,8 \\
\hline Anggota & 18 & 85,6 & 18 & 85,6 \\
\hline Jumlah & 21 & 100 & 21 & 100 \\
\hline Luas Lahan $\mathrm{m}^{2}$ & Tani Jaya & Persentase (\%) & Tani Makmur & Persentase $(\%)$ \\
\hline 3.300 & 7 & 33,3 & 10 & 47,6 \\
\hline 5.000 & 11 & 52,4 & 7 & 33,3 \\
\hline 10.000 & 3 & 14,3 & 4 & 19,1 \\
\hline Jumlah & 21 & 100 & 21 & 100 \\
\hline Rerata luas lahan & $5.147,62 \mathrm{~m}^{2}$ & & $5.142,86 \mathrm{~m}^{2}$ & \\
\hline
\end{tabular}

Sumber: Analisis Data Primer, 2018 
dapat mencapai Rp. 44.690.000,/Ha/MT. Sementara berdasarkan penelitian Rahmadona (2015) menyatakan pendapatan atas biaya total petani bawang merah di Kabupaten Majalengka, masing-masing usahatani yaitu Rp34,117,830.75 usahatani di Musim Hujan, Rp17,800,443.78 usahatani di Musim Kemarau I dan Rp12,886,452.69 usahatani Musim Kemarau II.

Tabel 3 Karakteristik Responden Berdasarkan Status Kepemilikan Lahan Petani Bawang Merah di Desa Pasir Kecamatan Mijen

\begin{tabular}{lcc}
\hline Status Kepemilikan Lahan & $\begin{array}{c}\text { Jumlah } \\
\text { (orang) }\end{array}$ & $\begin{array}{c}\text { Persentase } \\
(\%)\end{array}$ \\
\hline Sewa & 13 & 30,95 \\
Milik Sendiri & 29 & 60,05 \\
\hline Jumlah & 42 & 100 \\
\hline
\end{tabular}

Sumber: Analisis Data Primer, 2018

\section{Varietas Bawang Merah yang Lebih Banyak Ditanam oleh Petani}

Berdasarkan hasil penelitian, maka diperoleh data bahwa petani bawang merah di Desa Pasir Kecamatan Mijen Kabupaten Demak pada musim I (Oktober-Desember tahun 2017) petani lebih banyak menanam bawang merah Varietas Bima Brebes dengan jumlah 26 orang (61,9 persen). Sementara pada musim tanam II (pada bulan Febuari-April 2018), petani lebih banyak menanam varietas Bima Sawo. Jenis varietas bawang merah yang ditanam petani pada musim tanam pertama maupun musim tanam bawang merah kedua dapat dilihat secara terperinci pada Tabel 5.

Tabel 4 Bobot Atribut Rerata

Terhadap Karakteristik Bawang Merah

\begin{tabular}{lcc}
\hline Karakteristik & $\begin{array}{c}\text { Bobot Atribut } \\
\text { Rerata (BAR) }\end{array}$ & $\begin{array}{c}\text { Bobot Relatif } \\
\text { Atribut } \\
\text { (BRA) }\end{array}$ \\
\hline Tinggi Tanaman & 3,79 & 0,16 \\
Jumlah Anakan/umbi & 3,83 & 0,16 \\
Ketahanan HPT & 3,74 & 0,16 \\
Umur Panen & 4,19 & 0,18 \\
Hasil Produksi & 4,02 & 0,17 \\
Bibit mudah didapat & 3,76 & 0,16 \\
\hline
\end{tabular}

Sumber: Analisis Data Primer, 2018

Tabel 5 Jenis Varietas Bawang Merah yang Ditanam Petani Desa Pasir

\begin{tabular}{lcccc}
\hline \multirow{2}{*}{$\begin{array}{c}\text { Jenis } \\
\text { Varietas }\end{array}$} & $\begin{array}{c}\text { Jumlah } \\
\text { (orang) }\end{array}$ & $\begin{array}{c}\text { Persentase } \\
(\%)\end{array}$ & $\begin{array}{c}\text { Jumlah } \\
\text { (orang) }\end{array}$ & $\begin{array}{c}\text { Persentase } \\
(\%)\end{array}$ \\
\hline Bima Brebes & 26 & 61,9 & 15 & 35,7 \\
Bima Sawo & 10 & 23,8 & 21 & 50 \\
Bima Drajat & 4 & 9,5 & 5 & 11,9 \\
Bima Curut & 2 & 4,8 & 1 & 2,4 \\
\hline Jumlah & 42 & 100 & 42 & 100 \\
\hline Sumber: Analisim
\end{tabular}

Sumber: Analisis Data Primer, 2018 
Petani lebih memilih Bima Brebes pada musim tanam I (yang termasuk dalam musim hujan) dengan pertimbangan dari kualitasnya yang cukup tahan terhadap busuk umbi, serta potensi hasil dapat mencapai 9,9 ton/ha. Hal ini relevan dengan penelitian Basuki (2014) yang menyatakan persepsi petani Brebes, bahwa varietas bawang merah dari Balitsa yang paling baik kualitasnya adalah Bima Brebes. Semua atribut kualitas yang dipunyai Bima Brebes menurut penilaian petani berada diatas rerata. Atribut ukuran umbi, kepedasan, warna umbi, jumlah anakan, dan hasil umbi/produksi.

\section{Preferensi Petani Terhadap Karakteristik Beberapa Varietas Bawang Merah}

Sebelum mengetahui tingkat preferensi total maka terlebih dahulu mencari tingkat preferensi rerata dan rerata per atribut karakteristik dari semua varietas yang ditanam oleh petani yaitu varietas Bima Brebes, Bima Sawo, Bima Drajat, dan Bima Curut. Hal tersebut disajikan terperinci pada Tabel 6. Nilai Tingkat Preferensi Rerata (TPR) dan Tingkat Preferensi Rerata Atribut (TPRA) menunjukkan nilai tingkat preferensi masing-masing varietas bervariasi dan nilai keseluruhan. Nilai tingkat preferensi masingmasing varietas bervariasi, ada yang lebih tinggi atau lebih rendah bila dibandingkan dengan rerata keseluruhan varietas. Rentang kesukaan pada taraf biasa saja (3) sampai pada taraf di atas suka (4), namun tidak sampai pada taraf sangat suka (5). Nilai preferensi rerata varietas (TPR) yang lebih tinggi diatas nilai preferensi rerata atribut semua varietas (TPRA), berpeluang lebih besar untuk lebih disukai oleh petani.

Karakteristik suatu varietas bawang merah juga penting untuk diketahui karena karakteristik menentukan kesediaan petani menanam benih suatu varietas tertentu. Jika atribut kualitas tidak disukai petani maka petani tidak akan bersedia menanam varietas baru tersebut. Preferensi terhadap karakteristik beberapa varietas bawang merah ditampilkan pada Tabel 6. Hasil analisis data menunjukkan bahwa pada Varietas Bima Brebes, karakteristik umur panen $(4,07)$ dan hasil produksi $(4,19)$ dipilih sebagai karakter yang paling penting oleh petani. Varietas Bima Sawo, masing-masing karakteristik mempunyai nilai sama, tidak ada karakteristik yang dianggap penting oleh petani. Sementara varietas Bima Drajat, karakteristik jumlah anakan $(4,10)$ yang dipilih serta pada varietas Bima Curut, karakteristik ketahanan terhadap hama penyakit $(4,10)$ dan hasil produksi $(4,05)$.

Tabel 6 Nilai Tingkat Preferensi Rerata (TPR) dan Tingkat Preferensi Rerata Atribut (TPRA) Karakteristik Beberapa Varietas Bawang Merah.

\begin{tabular}{|c|c|c|c|c|c|}
\hline \multirow[b]{2}{*}{ Atribut Karakteristik } & \multicolumn{3}{|c|}{ TPR } & & \multirow[b]{2}{*}{ TPRA } \\
\hline & $\begin{array}{c}\text { Bima } \\
\text { Brebes }\end{array}$ & Bima Sawo & $\begin{array}{l}\text { Bima } \\
\text { Drajat }\end{array}$ & $\begin{array}{l}\text { Bima } \\
\text { Curut }\end{array}$ & \\
\hline Tinggi Tanaman & 3,43 & 3,62 & 3,81 & 3,67 & 3,63 \\
\hline Jumlah Anakan & 3,74 & 3,67 & 4,10 & 3,86 & 3,84 \\
\hline Ketahanan HPT & 3,71 & 3,90 & 3,74 & 4,10 & 3,86 \\
\hline Umur Panen & 4,07 & 3,36 & 3,90 & 3,71 & 3,76 \\
\hline Hasil Produksi & 4,19 & 3,98 & 3,67 & 4,05 & 3,97 \\
\hline Bibit mudah didapat & 3,45 & 3,45 & 3,60 & 3,69 & 3,55 \\
\hline
\end{tabular}


Selanjutnya pada Tabel 7 menunjukkan nilai Tingkat Preferensi Relatif (TPRel) petani terhadap atribut karakteristik beberapa varietas Bawang Merah. Berdasarkan data pada Tabel 7 dengan menghitung Tingkat Preferensi Relatif (TPRel) petani Desa Pasir terhadap masingmasing varietas, menunjukkan bahwa masingmasing varietas mempunyai keunggulan karakteristik yang berbeda-beda. Nilai TPRel yang lebih dari 1 menunjukkan bahwa nilai preferensi petani terhadap suatu atribut karakteristik lebih tinggi dari nilai preferensi rerata semua varietas.

Misalnya, nilai karakter tinggi tanaman varietas BimaDrajat 1,05 menunjukkan bahwa preferensi petani terhadap tinggi tanaman varietas Bima Drajat 5\% lebih tinggi di atas tingkat preferensi rerata semua varietas. Sementara karakteristik jumlah anakan, varietas Bima Drajat $(1,07)$ juga lebih tinggi $7 \%$ di atas tingkat preferensi rerata semua varietas.

Adapun bawang merah varietas Bima Curut, nilai karakteristik ketahanan bibit mudah didapat $(1,04), 4 \%$ lebih tinggi di atas tingkat preferensi rerata semua varietas. Pada karakter umur panen, varietas Bima Brebes mempunyai nilai 1,08 yang berarti $8 \%$ lebih tinggi dan hasil produksi varietas Bima Brebes yang menunjuk- kan angka 1,06 berarti 6\% lebih tinggi dari tingkat preferensi petani rerata semua varietas yang diuji.Adapun pada nilai TPRel yang kurang dari 1 seperti karakter tinggi tanaman pada varietas Bima Brebes menunjuk-kan angka 0,94 yang berarti $6 \%$ lebih rendah dari tingkat preferensi rerata semua varietas. Karakteristik varietas Bima Brebes yang mempunyai tingkat preferensi lebih tinggi dari tingkat preferensi rerata adalah umur panen dan hasil produksi. Adapun umur panen tanaman bawang merah varietas Bima Brebes adalah 60 HST dan produksi kering varietas Bima Brebes dapat mencapai 9,9 ton/Ha (Direktorat Jendral Hortikultura Kementerian Pertanian, 2018).

Karakteristik varietas Bima Sawo mempunyai nilai lebih tinggi dari tingkat preferensi rerata pada karakteristik tinggi tanaman, ketahanan terhadap hama penyakit, hasil produksi dan bibit mudah diperoleh. Karakteristik varietas Bima Drajat yang mempunyai nilai lebih tinggi dari tingkat preferensi rerata adalah tinggi tanaman, jumlah anakan, umur panen dan bibit mudah diperoleh. Sementara karakteristik varietas Bima Curut yang mempunyai nilai lebih tinggi dari tingkat preferensi rerata adalah tinggi tanaman, jumlah anakan, ketahanan terhadap hama penyakit, hasil produksi dan bibit mudah

Tabel 7 Nilai Tingkat Preferensi Relatif (TPRel) Atribut Karakteristik Beberapa Varietas Bawang Merah

\begin{tabular}{lcccc}
\hline \multirow{2}{*}{ Atribut Karakteristik } & \multicolumn{4}{c}{ TPRel } \\
\cline { 2 - 5 } & Bima Brebes & Bima Sawo & Bima Drajat & Bima Curut \\
\hline Tinggi Tanaman & 0,94 & 1,00 & 1,05 & 1,01 \\
Jumlah Anakan & 0,97 & 0,96 & 1,07 & 1,00 \\
Ketahanan HPT & 0,96 & 1,01 & 0,97 & 1,06 \\
Umur Panen & 1,08 & 0,89 & 1,04 & 0,99 \\
Hasil Produksi & 1,06 & 1,00 & 0,92 & 1,02 \\
Bibit mudah didapat & 0,97 & 0,97 & 1,01 & 1,04 \\
\hline
\end{tabular}

Sumber: Analisis Data Primer, 2018 
Tabel 8 Nilai Tingkat Preferensi Relatif(TPRel) Atribut Karakteristik

Beberapa Varietas Bawang Merah

\begin{tabular}{lccccc}
\hline \multirow{2}{*}{ Atribut Karakteristik } & TPRA & $\begin{array}{c}\text { Bima } \\
\text { Brebes }\end{array}$ & $\begin{array}{c}\text { Bima } \\
\text { Sawo }\end{array}$ & $\begin{array}{c}\text { Bima } \\
\text { Drajat }\end{array}$ & $\begin{array}{c}\text { Bima } \\
\text { Curut }\end{array}$ \\
\cline { 3 - 6 } & Tinggi Tanaman & 0,94 & 1,00 & 1,05 & 1,01 \\
Jumlah Anakan & 3,63 & 0,97 & 0,96 & 1,07 & 1,00 \\
Ketahanan HPT & 3,86 & 0,96 & 1,01 & 0,97 & 1,06 \\
Umur Panen & 3,76 & 1,08 & 0,89 & 1,04 & 0,99 \\
Hasil Produksi & 3,97 & 1,06 & 1,00 & 0,92 & 1,02 \\
Bibit mudah didapat & 3,55 & 0,97 & 0,97 & 1,01 & 1,04 \\
\hline
\end{tabular}

Sumber: Analisis Data Primer, 2018

diperoleh. Ada beberapa karakteristik kualitas yang sama atau hampir sama antara varietas satu dengan yang lain.

Selanjutnya mengenai nilai Tingkat Preferensi Total (TPT) dapat diperoleh dengan menjumlahkan nilai tingkat preferensi relatif dibobot (TPRD) masing-masing varietas. Sementara nilai preferensi relatif dibobot berasal dari nilai tingkat preferensi relatif masing-masing varietas dikalikan nilai bobot relatif atribut (BRA). Nilai bobot relatif atribut akan menunjukkan persepsi seberapa penting suatu atribut terhadap kesukaan petani, sehingga tingkat preferensi total merupakan kombinasi dari seberapa suka dan berapa penting suatu karakteristik tanaman yang menjadikan varietas tertentu merupakan varietas yang secara umum paling disukai oleh petani
Desa Pasir. Nilai TPRD dari beberapa varietas bawang merah dapat dilihat pada Tabel 9.

Perhitungan tingkat preferensi total yang ditampilkan dalam Tabel 9, menunjukkan bahwa TPT nilai varietas Bima Brebes $(1,00)$, Bima Sawo $(0,97)$, Bima Drajat $(1,01)$ dan Bima Curut (1,02). Hal ini menunjukkan dari keseluruhan karakteristik/atribut bawang merah maka varietas Bima Curut yang paling disukai dengan nilai 1,02 dibandingkan Bima Drajat $(1,01)$, Bima Brebes $(1,00)$ dan Bima Sawo $(0,97)$. Varietas Bima Curut memiliki banyak karakteristik atribut yang mempengaruhi petani dalam memilih varietas bawang merah. Sebaliknya dengan petani bawang merah di Desa Gajah Kecamatan Gajah, dalam penelitian Awami (2018) mengenai Faktor Yang Mempengaruhi Produksi Bawang Merah

Tabel 9 Nilai Tingkat Preferensi Relatif Dibobot (TPRD) Atribut Karakteristik Beberapa Varietas Bawang Merah

\begin{tabular}{lcccc}
\hline \multirow{2}{*}{ Atribut Karakteristik } & \multicolumn{5}{c}{ TPRD } \\
\cline { 2 - 5 } & $\begin{array}{c}\text { Bima } \\
\text { Brebes }\end{array}$ & Bima Sawo & Bima Drajat & $\begin{array}{c}\text { Bima } \\
\text { Curut }\end{array}$ \\
\hline Tinggi Tanaman & 0,14 & 0,16 & 0,18 & 0,16 \\
Jumlah Anakan & 0,16 & 0,16 & 0,19 & 0,17 \\
Ketahanan HPT & 0,16 & 0,18 & 0,16 & 0,19 \\
Umur Panen & 0,20 & 0,14 & 0,18 & 0,16 \\
Hasil Produksi & 0,20 & 0,18 & 0,15 & 0,18 \\
Bibit mudah didapat & 0,15 & 0,15 & 0,16 & 0,17 \\
\hline TPT & 1,00 & 0,97 & 1,01 & 1,02 \\
\hline
\end{tabular}

Sumber: Analisis Data Primer, 2018 
(Allium ascalonium L) di Kabupaten Demak, selain variabel luas lahan, bibit, pupuk, status kepemilikan lahan, varietas bawang merah juga turut mempengaruhi. Hasil koefisien regresi mengartikan, bahwa petani yang mengusahakan usahatani bawang merah sebaiknya menggunakan varietas Bima Sawo dan Sarkonah daripada menggunakan varietas Bima Curut.

\section{KESIMPULAN}

1. Karakteristik atribut pada tanaman bawang merah yang dianggap penting oleh petani yaitu umur panen $(0,18)$ dan hasil produksi $(0,17)$.

2. Pada musim tanam I, petani bawang merah lebih banyak menanam Varietas Bima Brebes, yang mempunyai preferensi tertinggi sebanyak 26 responden (61,9 persen). Varietas kedua yang banyak ditanam petani adalah varietas Bima Sawo, yaitu sebanyak 10 responden (23,8 persen). Sementara musim tanam II petani bawang merah lebih banyak yang menanam bawang merah varietas Bima Sawo, atau sebanyak 21 responden (50 persen) sedangkan untuk Varietas Bima Brebes sebesar 15 orang atau 35,71 persen.

3. Nilai tingkat preferensi total yang diperoleh menunjukkan bahwa TPT nilai varietas Bima Brebes $(1,00)$, Bima Sawo $(0,97)$, Bima Drajat (1,01) dan Bima Curut (1,02). Hal ini menunjukkan dari keseluruhan karakteristik/atribut bawang merah maka varietas Bima Curut yang paling disukai dengan nilai 1,02 dibandingkan Bima Drajat $(1,01)$, Bima Brebes $(1,00)$ dan Bima Sawo $(0,97)$.

\section{DAFTAR PUSTAKA}

Awami, Shofia Nur, Khalimatus Sa'diyah, Endah Subekti. 2018. Faktor Yang Mempengaruhi Produksi Bawang Merah (Allium ascalonium L) di Kabupaten Demak. Jurnal Agrifo. November Vol. 3 No. 2 (35-44). Fakultas Pertanian Universitas Malikussaleh. Aceh.

Basuki, RS, Khaririyatun, N, dan Luthfy. 2014. Evaluasi dan Preferensi Petani Brebes Terhadap Atribut Kualitas Varietas Unggul Bawang Merah Hasil Penelitian Balitsa. Jurnal Hortikultura. 24(3): 276-282.

Dinas Pertanian. 2016. Data Statistik Kantor Dinas Pertanian Kabupaten Demak. Demak.

Direktorat Jendral Hortikultura Kementerian Pertanian, 2018. Kelembagaan Benih Bermutu Bawang Merah. Direktorat Perbenihan Hortikultura- Direktorat Jenderal Hortikultura. E-book. [November 22, 2018].

Fachrista, I. A., Issukindarsyah, Rusmawan D., Dewi HA 2012. Preferensi Petani Kabupaten Bangka Selatan Terhadap Beberapa Varietas Unggul Padi Sawah. Prosiding Seminar Nasional "Kedaulatan Pangan dan Energi". Fakultas Pertanian Universitas Trunojoyo Madura. Madura, Juni 2012.

Pemerintah Desa Pasir. 2017. Monografi Desa Pasir. Kecamatan Mijen Kabupaten Demak. Demak.

Pusat Data dan Sistem Informasi Pertanian. 2015. Outlook Komoditas Pertanian Subsektor Hortikultura Bawang 
Merah. Pusat Data dan Sistem Informasi

Pertanian Sekretariat Jenderal -

Kementerian Pertanian. Jakarta.

Rahmadona, Lola., AnnaFariyanti, Burhanuddin. 2015. Analisis Pendapatan Usahatani Bawang Merah di Kabupaten Majalengka. Jurnal Agrise. Vol. XV. No. 2. Mei.
Setyorini, Dewi Tri. 2018. Analisis Pendapatan Usahatani Bawang Merah (Allium ascalonicum L.) (Studi Kasus Pada Kelompok Tani Jaya Desa Pasir Kecamatan Mijen Kabupaten Demak). Unpublished thesis, Fakultas Pertanian Universitas Wahid Hasyim, Semarang. Simamora, B. 2002. Panduan Riset Konsumen. PT. Gramedia Satria Utama, Jakarta. 